\title{
Maternal and Child Healthcare Service by Portable Health Clinic System Using a Triage Protocol
}

\author{
Rafiqul ISLAM ${ }^{\mathrm{a}, 1}$, Kimiyo KIKUCHI ${ }^{\mathrm{b}}$, Yoko SATO $^{\mathrm{b}}$, Rieko IZUKURA $^{\mathrm{a}}$, \\ Nusrat JAHAN ${ }^{\mathrm{c}}$, Nazneen SULTANA ${ }^{\mathrm{c}}$, Meherun NESSA ${ }^{\mathrm{d}}$, Fumihiko YOKOTA ${ }^{\mathrm{e}}$, \\ Mariko NISHIKITANI $^{\mathrm{a}}$, Ashir AHMED $^{\mathrm{f}}$ and Naoki NAKASHIMA ${ }^{\mathrm{a}}$ \\ ${ }^{a}$ Medical Information Center, Kyushu University Hospital, Japan \\ ${ }^{\mathrm{b}}$ Graduate School of Medical Science, Kyushu University, Japan \\ ${ }^{\mathrm{c}}$ Grameeen Communications, Bangladesh \\ ${ }^{\mathrm{d}}$ Holy Family Red Crescent Medical College \& Hospital, Bangladesh \\ ' Institute of Asian Oceanian Studies, Kyushu University, Japan \\ ${ }^{\mathrm{f}}$ Graduate School of Info. Science \& Elec. Engg., Kyushu University, Japan
}

\begin{abstract}
The number of deaths of a mother and child caused by maternal and child healthcare $(\mathrm{MCH})$ issues has been greatly decreased recently, but still, the number is extremely high especially in developing countries. Although the governments have been given a priority in this issue, the lack of financial and human resources brings a limit. Thus, the use of low-cost but appropriate technology is required. Portable Health Clinic (PHC), a telemedicine system developed for providing primary healthcare, is such a technology. This study aimed to address this $\mathrm{MCH}$ issue with the aid of a low-cost PHC service involving a continuum-of-care protocol to the rural communities of Bangladesh. Moreover, this study introduces a triage protocol to distinguish high-risk patients from the early stage of the continuum of care who need special care and refer to specialized physicians to prevent unwanted deaths.
\end{abstract}

Keywords. Telemedicine, MCH triage, decision support, preventive healthcare

\section{Introduction}

Globally, the number of annual deaths of women caused by maternal issues is approximately 295,000 [1]. Conversely, the annual deaths of children aged $<5$ years are approximately 5,300,000. Among these, approximately $47 \%$ of deaths occur within the first 1 month of life or during the neonatal period. Unfortunately, the majority of these deaths occurs in underdeveloped or developing countries. Moreover, most of these deaths could be prevented if access to healthcare services was ensured [2]. Therefore, this issue has been strongly addressed in Sustainable Development Goals, and the United Nations has called to reduce the global maternal mortality ratio (to $<70$ per 100,000 live births) and neonatal mortality (12 per 1000 live births) by 2030 [3].

\footnotetext{
${ }^{1}$ Corresponding Author, Rafiqul Islam, Associate Professor, Medical Information Center, Kyushu University Hospital, 3-1-1 Maidashi, Higashi-Ku, Fukuoka 812-8582, Japan; E-mail: rimaruf@med.kyushuu-ac.jp.
} 
The concept of the continuum of care has been proposed as a way to globally improve maternal and child health $(\mathrm{MCH})$ [4]. The continuum of care is an integrated series of care steps in multiple stages throughout life: adolescence/prepregnancy, pregnancy, delivery, postpartum, childhood, and motherhood. Because of its ability to reach patients at different stages, the use of the continuum of care is an effective strategy to improve $\mathrm{MCH}$. The $\mathrm{MCH}$ module of the Portable Health Clinic (PHC) system has been developed for this purpose. As there is a huge shortage of obstetrics and gynecology in low economies, it needs to make the best use of these valued resources. This study introduces a triage protocol for the $\mathrm{MCH}$ module for classifying patients in terms of disease severity. Patients who will be identified as high-risk patients will be connected to specialist physicians for teleconsultancy. Patients who are not at high risk will be followed by local health workers or attend teleconsultancy from general physicians.

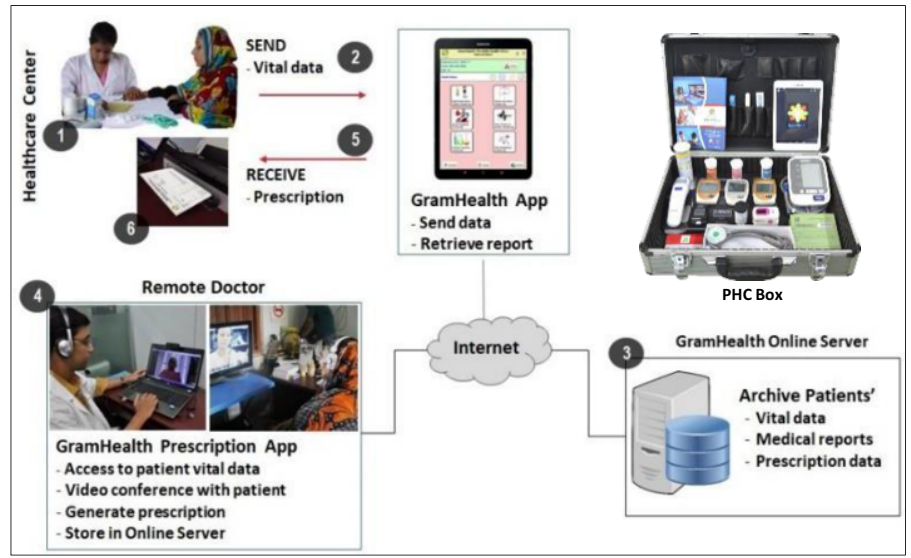

Figure 1. Portable health clinic workflow.

\section{Methods}

\subsection{Portable Health Clinic}

The PHC has been developed as a telehealthcare system for unreached rural communities of Bangladesh [5]. Initially, it was designed for primary healthcare with a special focus on preventive care for noncommunicable diseases (NCDs).

In this service delivery system, a trained village health worker visits patients at their home with a PHC box equipped with a number of medical sensors. Then, the health worker (1) collects various vital information from patients using digital sensors and questionnaire; (2) enters the data to the PHC application, which classifies the patients in four categories on risk level, namely, green (healthy), yellow (caution), orange (affected), and red (emergent) using a triage system; and (3) stores the data on the online server; (4) in case of green and yellow patients, the health worker supports the patients; otherwise, the remote physician monitors the vital data, holds a video conference with the patients, and writes an e-prescription, and (5) the prescription is printed to be delivered to the patient by the health worker with a verbal explanation (Figure 1). Thus, the patient can obtain total service, including checkup, diagnosis, and consultancy, in a few minutes being at home. 


\subsection{MCH Module}

There is a huge need for MCH service in rural communities. As there is no specialized $\mathrm{MCH}$ service in the local medical facilities, in most cases, village women depend on local midwives who mostly do not have any professional training. If they like to consult any specialist (Obs and Gyne), they need to visit a district or subdistrict, which is far and expensive for this low-income group. Therefore, PHC staff receive a huge request for this specialized service by this system, and thus, this $\mathrm{MCH}$ module has been developed.

The PHC basic module has been equipped with basic medical sensors for collecting 14 common vital information in the context of Bangladesh. These are as follows: body mass index, body temperature, hip-waist ratio, blood pressure, pulse rate, arrhythmia, blood oxygenation, blood glucose (random), urinary sugar, urinary protein, blood group, cholesterol, hemoglobin, and uric acid. The $\mathrm{MCH}$ module just includes handheld ultrasound, fetal Doppler, infant height measure meter and infant scale.

Table 1. Triage logic for antenatal care patients in $\mathrm{MCH}$ module of the PHC system.

\begin{tabular}{|c|c|c|c|c|c|c|c|}
\hline Stage & \multicolumn{2}{|c|}{ Checkup Items } & Unit & $\begin{array}{c}\text { Green } \\
\text { (Healthy) }\end{array}$ & $\begin{array}{c}\text { Yellow } \\
\text { (Caution) }\end{array}$ & $\begin{array}{c}\text { Orange } \\
\text { (Affected) }\end{array}$ & $\begin{array}{c}\text { Red } \\
\text { (Fmergent }\end{array}$ \\
\hline \multirow{25}{*}{ 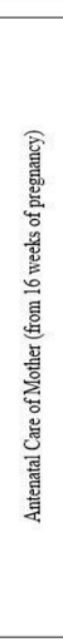 } & Exp & ted Date of Delivery & Calculatic & 280 days to th & irst day of last $m$ & trual period & \\
\hline & \multirow{2}{*}{\multicolumn{2}{|c|}{ Blood Pressure (H/D) }} & \multirow{2}{*}{$\mathrm{mmHg}$} & $<120$ & $\geqq 120 \& \leqq 129$ & $\geqq 130 \& \leqq 139$ & $\geqq 140$ \\
\hline & & & & $<80$ & & $\geqq 80 \& \leqq 89$ & $\geqq 90$ \\
\hline & \multicolumn{2}{|c|}{ Pulse } & bpm & $\geqq 60 \&<100$ & $\begin{array}{l}\geqq 50 \&<<60 \| \\
\geqq 100 \&<120\end{array}$ & $<50 \| \geqq 120$ & \\
\hline & \multicolumn{2}{|c|}{$\begin{array}{l}\text { Temperature } \\
\text { Hemoglobin }\end{array}$} & ${ }^{\circ} \mathrm{C}$ & $<37.0$ & $\geqq 37.0 \&<<37.5$ & $\geqq 37.5 \&<38.0$ & $\geqq 38.0$ \\
\hline & Hen & globin & $\mathrm{g} / \mathrm{dl}$ & $\geqq 11$ & $<11 \& \geqq 10$ & $<10 \& \geqq 8$ & $<8.0$ \\
\hline & \multicolumn{2}{|c|}{ Urine Protein } & & Negative & \pm & + & $++\|+++$ \\
\hline & \multicolumn{2}{|c|}{ Urine Sugar } & & Negative & \pm & + & $++\|+++$ \\
\hline & \multirow{2}{*}{\multicolumn{2}{|c|}{ Blood Glucose (PBS/FBS) }} & & $<5.56$ & $\geqq 5.56 \&<7.0$ & $\geqq 7.0 \&<11.11$ & $\geqq 11.11$ \\
\hline & & & $\mathrm{mmol} / \mathrm{dl}$ & $<5.1$ & & $\geqq 5.1 \&<7.0$ & $\geqq 7.0$ \\
\hline & \multicolumn{2}{|c|}{ BMI (Pre-Pregnancy BMI) } & $\mathrm{Kg} / \mathrm{m} 2$ & $\geqq 18.5 \&<25$ & $\begin{array}{c}\geqq 25 \&<30 \| \\
<18.5\end{array}$ & $\geqq 30$ & \\
\hline & \multicolumn{2}{|c|}{ Fetus Beat / Minute } & bpm & $\begin{array}{l}\geqq 110 \& \\
\leqq 160\end{array}$ & & $<110 \|>160$ & \\
\hline & \multicolumn{2}{|c|}{ Height of Uterus } & $\mathrm{cm}$ & & & & \\
\hline & \multicolumn{2}{|c|}{$\begin{array}{l}\text { Swelling of Fingers, Face and } \\
\text { Legs (Edema) }\end{array}$} & & No & & Yes & \\
\hline & \multicolumn{2}{|c|}{ Position of Baby } & & Normal & & Breech & \\
\hline & \multirow{10}{*}{ 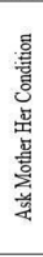 } & Movement of Baby & & Yes & & $\begin{array}{l}\text { No (for more } \\
\text { than } 1 \text { hour) }\end{array}$ & \\
\hline & & Regular Contractions & & No & & Yes & \\
\hline & & Rupture & & No & & Yes & \\
\hline & & Vaginal Bleeding & & No & & Yes & \\
\hline & & Smell Vaginal Discharge & & & & & \\
\hline & & $\begin{array}{l}\text { Severe Headache with } \\
\text { Blurred Vision }\end{array}$ & & No & & Yes & \\
\hline & & Severe Abdominal Pain & & No & & Yes & \\
\hline & & Vomiting & & No & & Yes & \\
\hline & & $\begin{array}{l}\text { Fever and too Weak to } \\
\text { Get Out of Bed }\end{array}$ & & No & & Yes & \\
\hline & & Convulsions & & No & & Yes & \\
\hline
\end{tabular}

\subsubsection{Service Protocol of MCH Module}

The MCH module basically follows the eight WHO- proposed stages of antenatal and postnatal checkup protocol for continuum of care using a telemedicine system. These checkups occur (1) within 4 months, (2) 6 months, (3) 8 months, and (4) 9 months of pregnancy; (5) right after delivery; (6) 2 days after delivery; (7) 7 days after delivery; and (8) 6 weeks after delivery. The newborn baby's health checkup is also conducted together with the mother in the four final stages. The patients receive home delivery service by female health workers at their own premises. The consulting physician connects to the patients from the city and if needed, they refer to the nearest hospital.

\subsubsection{Antenatal and Postnatal Triage Logic}

Like any other developing country, Bangladesh has a huge shortage of medical physicians and nurses. Therefore, it is greatly important to make the best use of these valued human resources. Like basic PHC, the MCH system has also adopted a triage 
system to classify the health status of the patients into four categories based on their severity. The orange and red patients are considered high-risk patients who need physician's consultation. However, patients who fall under green and yellow categories are considered comparatively safe and are served by the village healthcare worker.

Table 2. Triage logic for postnatal care patients in $\mathrm{MCH}$ module of the PHC system.

\begin{tabular}{|c|c|c|c|c|c|c|}
\hline Stage & Checkup Items & Unit & $\begin{array}{c}\text { Green } \\
\text { (Healthy) }\end{array}$ & $\begin{array}{c}\text { Yellow } \\
\text { (Caution) }\end{array}$ & $\begin{array}{c}\text { Orange } \\
\text { (Affected) }\end{array}$ & $\begin{array}{c}\text { Red } \\
\text { Fmergent) }\end{array}$ \\
\hline \multirow{23}{*}{ 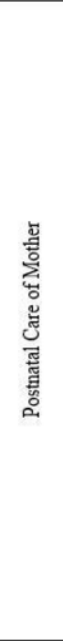 } & \multirow{2}{*}{ Blood Pressure (H/D) } & \multirow{2}{*}{$\mathrm{mmHg}$} & $<120$ & $\geqq 120 \& \leqq 129$ & $\geqq 130 \& \leqq 139$ & $\geqq 140$ \\
\hline & & & $<80$ & & $\geqq 80 \& \leqq 89$ & $\geqq 90$ \\
\hline & Pulse & bpm & $\geqq 60 \&<100$ & $\geqq 50 \&<<60 \|$ & $<50 \|>=120$ & \\
\hline & Temperature & ${ }^{\circ} \mathrm{C}$ & $<37.0$ & $\geqq 37.0 \&<37.5$ & $\geqq 37.5 \&<38.0$ & $\geqq 38.0$ \\
\hline & Hemoglobin & $\mathrm{g} / \mathrm{dl}$ & $\geqq 11$ & $<11 \& \geqq 10$ & $<10 \& \geqq 8$ & $<8.0$ \\
\hline & Urine Protein & & Negative & \pm & + & $++\|+++$ \\
\hline & Urine Sugar & & Negative & \pm & + & $++\|+++$ \\
\hline & \multirow{2}{*}{ Blood Glucose (PBS/FBS) } & \multirow{2}{*}{$\mathrm{mmol} / \mathrm{dl}$} & $<5.56$ & $\geqq 5.56 \&<7.0$ & $\geqq 7.0 \&<11.11$ & $\geqq 11.11$ \\
\hline & & & $<5.56$ & $\geqq 5.56 \&<6.11$ & $\geqq 6.11 \&<7.0$ & $\geqq 7.0$ \\
\hline & Weight & $\mathrm{kg}$ & & & & \\
\hline & Smelly Vaginal Discharge & & No & & Yes & \\
\hline & Amount of Bleeding & & $-\| \pm$ & + & ++ & \\
\hline & Hardness of Uterus & & Hard & & Soft & \\
\hline & Nutrition & \multicolumn{5}{|c|}{ Breastfeeding / Mixed / Formula } \\
\hline & $\begin{array}{l}\text { Swollen, Red or Tender Breasts } \\
\text { or Nipples }\end{array}$ & & No & & Yes & \\
\hline & Perineum Tear Problem & & No & & Yes & \\
\hline & Infection in the Area of Wound & & No & & Yes & \\
\hline & Problem in Urinating or Leaking & & No & & Yes & \\
\hline & Calf Pain, Redness or Swelling & & No & & Yes & \\
\hline & $\begin{array}{l}\text { Severe Headache with Blurred } \\
\text { Vision }\end{array}$ & & No & & Yes & \\
\hline & $\begin{array}{l}\text { Shortness of Breath or Chest } \\
\text { Pain }\end{array}$ & & No & & Yes & \\
\hline & $\begin{array}{l}\text { Fever and too Weak to Get Out } \\
\text { of Bed }\end{array}$ & & No & & Yes & \\
\hline & Convulsion & & No & & Yes & \\
\hline
\end{tabular}

The triage logic for the antenatal care of the mother and postnatal care of both the mother and baby are different. These protocols are shown in Tables 1, 2, and 3, respectively. These logics are incorporated in the $\mathrm{MCH}$ module of the $\mathrm{PHC}$ system so that the village health workers can easily identify the risk level of the individual patients with assistance of the system and refer the critical cases to the distanced experts.

Table 3. Triage logic for postnatal care of infant in $\mathrm{MCH}$ module of the PHC system.

\begin{tabular}{|c|c|c|c|c|c|c|c|}
\hline Stage & \multicolumn{2}{|c|}{ Checkup Items } & Unit & $\begin{array}{c}\text { Green } \\
\text { (Healthy) }\end{array}$ & $\begin{array}{c}\text { Yellow } \\
\text { (Caution) }\end{array}$ & $\begin{array}{l}\text { Orange } \\
\text { (Affected) }\end{array}$ & $\begin{array}{c}\text { Red } \\
\text { (Emergent) }\end{array}$ \\
\hline \multirow{8}{*}{ 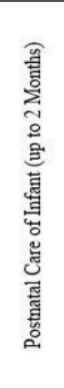 } & \multicolumn{2}{|c|}{ Height } & $\begin{array}{l}\text { WHO } \\
\text { Curve }\end{array}$ & \pm & $+1-$ & ++ or - & \\
\hline & \multicolumn{2}{|c|}{$\begin{array}{l}\text { Cyanosis: Dark Purple Color in } \\
\text { One of the Parts Indicated }\end{array}$} & & No & & Palm / Toes & $\begin{array}{l}\text { Mouth, Nose, } \\
\text { Face, Tongue }\end{array}$ \\
\hline & \multirow{6}{*}{ 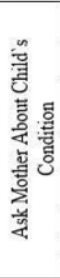 } & $\begin{array}{l}\text { Difficulty in Breathing } \\
\text { or Indrawing }\end{array}$ & & $\geqq 40 \&<60$ & & $<40 \| \geqq 60$ & \\
\hline & & $\begin{array}{l}\text { Yellow Color in One of } \\
\text { the Indicated Parts }\end{array}$ & & No & & $\begin{array}{c}\text { Eyeball } \\
\text { Conjunctiva/ } \\
\text { Forehead }\end{array}$ & $\begin{array}{l}\text { Trunk / Limbs } \\
\text { / Palms / Sole }\end{array}$ \\
\hline & & $\begin{array}{l}\text { Pus Coming from the } \\
\text { Eyes or Skin Pustules }\end{array}$ & & No & & Yes & \\
\hline & & $\begin{array}{l}\text { Irritated Cord with Pus } \\
\text { or Blood }\end{array}$ & & No & & Yes & \\
\hline & & Diarrhea & & No & & Yes & \\
\hline & & Convulsions & & No & & Yes & \\
\hline
\end{tabular}

\section{Results}

In this study, we have offered basic healthcare service to 630 productive age women aged 15-49 years in a rural community of $>14,000$ people in Bangladesh. Of them, we have offered specific $\mathrm{MCH}$ care services to 175 pregnant women (cohort) until the end of 
March 2021. This triage process identified $84(48 \%)$ patients in the orange category and $14(8 \%)$ patients in the red category who needed special consultation from professional physicians at least once during the antenatal period. The major causes identified for the problems were high blood pressure, low hemoglobin saturation, and high blood sugar level.

A total of 134 women have given birth without any stillbirth, and the rests are under antenatal care. Of these 134 births, two babies died within an hour of birth in the hospital due to the absence of emergency support facilities during the COVID-19 pandemic. As the COVID-19 pandemic is an extraordinary situation, this incidence can be considered out of the scope of this study. Moreover, we have found no reported death of any mother during delivery in this study.

\section{Discussion}

Bangladesh has significantly improved the infant mortality rate in the country, but still, it is 25.6 per 1000 in 2019 [6]. Currently the rate of decrease is extremely low and this is important to take new measures to bring a rapid improvement. The present result shows a significantly lower infant mortality rate achieved by this $\mathrm{MCH}$ service. Moreover, the result shows zero maternal death. One of the main reasons for this improvement is that the patients do not miss any continuum care as they receive the service at their home. Besides, this technical assistance to the village health workers by this automated triage system is very important to respond to the sensitive differences in various stages of the continuum of care what is very difficult to manage manually.

\section{Conclusion}

Although Bangladesh has a poor physician-patient ratio, the physician-nurse ratio is worse. Therefore, there is an urgent need to train and empower the existing rural health workers to tackle the current situation. The PHC system can play a significant role in this purpose and empower the rural health workers with this technology, especially for primary healthcare with a focus on the $\mathrm{MCH}$ service.

\section{References}

[1] Trends in maternal mortality: 2000 to 2017: Estimates by WHO, UNICEF, UNFPA, World Bank Group and the United Nations Population Division. Geneva: World Health Organization; 2019.

[2] Bhutta ZA, Das JK, Bahl R et al. Can available interventions end preventable deaths in mothers, newborn babies, and stillbirths, and at what cost? Lancet. 2014;384(9940):347-70.

[3] Sustainable development goal 3: Ensure healthy lives and promote well-being for all at all ages. https://www.un.org/sustainabledevelopment/health/ (2020)

[4] Kerber KJ, de Graft-Johñson JE, Bhutta ZA, Okong P, Starrs A, Lawn JE. Continuum of care for maternal, newborn, and child health: From slogan to service delivery. Lancet. 2007;370(9595):1358-69.

[5] Islam R, Nohara Y, Rahman MJ, Sultana N, Ahmed A, Nakashima N. "Portable health clinic: An advanced tele-healthcare system for unreached communities." EBook: MEDINFO 2019: Health \& Wellbeing e-Network for All, Volume 264 (2019), 416-9.

[6] Estimates developed by the UN Inter-agency Group for Child Mortality Estimation (UNICEF, WHO, World Bank, UN DESA Population Division): Mortality rate, infant (per 1,000 live births) - Bangladesh. https://data.worldbank.org/indicator/SP.DYN.IMRT.IN?locations=BD (2021). 